УДК [37.016:78]-027.541

DOI 10.37972/chgpu.2020.109.4.019

Е. В. Бакшаева

\begin{abstract}
СОЦИАЛЬНО-КУЛЬТУРНЫЕ ДОМИНАНТЫ В СОДЕРЖАНИИ РЕГИОНАЛЬНОЙ ПРОГРАММЫ ОБЩЕГО МУЗЫКАЛЬНОГО ОБРАЗОВАНИЯ
\end{abstract}

\author{
Чувашский государственный педагогический университет \\ им. И. Я. Яковлева, г. Чебоксары, Россия
}

\begin{abstract}
Аннотация. В статье раскрывается проблема определения содержания региональной программы общего музыкального образования путем обоснования ее социально-культурных доминант. На основе рассмотрения действующих программ «Музыка» в Чувашской Республике в контексте их социально-культурных ориентиров дается описание факультативного курса «Музыкальное путешествие по родному краю» для начальных классов общеобразовательных школ Чувашии, который базируется на национальном музыкально-художественном материале. Данный факультативный курс опирается на результаты факторного анализа, обосновывающего те социально-культурные доминанты содержания курса, которые направлены на формирование у детей комплекса как музыкальных, так и этнокультурных знаний, умений и представлений в области национальной культуры. Основой исследования послужили научные труды по методике и методологии художественного образования Э. Б. Абдуллина, О. А. Апраксиной, Л. Г. Арчажниковой, Л. В. Кузнецовой. В результате исследования был проведен факторный анализ действующих данных программ по музыке, который показал следующее: глобализация образования, затрагивающая школьные предметы гуманитарного и художественно-эстетического циклов, не должна стирать этническое своеобразие народных культур, что ярко представлено их музыкальными традициями, направленными на воспитание в ребенке любви к родному краю, к Отечеству; в некоторых из анализируемых программ не в полной мере применяются принцип художественной интеграции на уроках музыки и метод художественного контекста. Тем самым не уделяется должного внимания культуроемкости региональных программ школьного музыкального образования. Исходя из этого актуальными социально-культурными основами, т. е. доминантами содержания региональной программы общего музыкального образования определены следующие: воспитание патриотов своей малой родины и России; гуманистическая, культуротворческая направленность профессиональной деятельности педагога-музыканта; этнокультурная толерантность как механизм формирования гражданского самосознания обучающихся. Проведенное исследование обладает практической значимостью и может быть использовано в различных образовательных организациях республики: в детских общеобразовательных школах, детских школах искусств, в курсах методики музыкального обучения и воспитания в музыкальнопедагогических колледжах, на факультетах музыкального образования и начальных классов педагогических вузов, в содержании курсов специализации и повышения квалификации учителей музыки.
\end{abstract}

Ключевые слова: социально-культурные доминанты, региональные программы, общее музыкальное образование, факультативный курс «Музыкальное путешествие по родному краю».

E. V. Bakshaeva

\title{
SOCIO-CULTURAL DOMINANTS IN THE REGIONAL PROGRAMME OF GENERAL MUSIC EDUCATION
}

\section{Yakovlev CHSPU, Cheboksary, Russia}

\begin{abstract}
The article reveals the problem of determining the content of the regional programme of general music education by substantiating its socio-cultural dominants. Considering of the existing
\end{abstract}


programmes "Music" in the Chuvash Republic, in the context of their socio-cultural guidelines, the author describes an optional course "Musical Journey to the Native Land" for the primary classes of general education schools in Chuvashia, which is based on national musical and artistic material. This optional course is based on the results of a factor analysis that justifies the socio-cultural dominants of the course content, which are aimed at the formation of a complex of both musical and ethnocultural knowledge, skills and ideas in the field of national culture in children. The research was based on scientific works on methodology of art education: E. B. Abdullin, O. A. Apraksina, L. G. Archazhnikova, L. V. Kuznetsova. As a result of the study, a factor analysis of the current data of music programmes was carried out. It showed that the globalization of education, affecting school subjects of humanitarian and artistic-aesthetic cycles, should not erase the ethnic originality of folk cultures, which is clearly represented by their musical traditions aimed at cultivation of love for their native land in a child, for the Fatherland; in some of the analyzed programmes, the principle of artistic integration in music lessons is not sufficiently used, as well as the method of artistic context. Thus, the cultural intensity of regional school music education programmes is not given due attention. Hence, the following are determined by the relevant socio-cultural foundations, that is, the dominants of the content of the regional programme of general musical education: education of patriots of both their small homeland and Russia; humanistic, cultural and creative orientation of professional activity of teacher-musician; ethno-cultural tolerance as a mechanism for the formation of civic identity of pupils. The study has practical significance and can be used in various educational systems of the republic: at children's general education schools, children's art schools, at courses on the methodology of musical education and education in music and pedagogical colleges, faculties of music education and primary classes of pedagogical universities, in the content of courses of specialization and advanced training of music teachers.

Keywords: socio-cultural dominants, regional programmes, general music education, optional course "Musical Journey to the Native Land".

Введение. Предметом наших изысканий стала проблема определения содержания региональной программы общего музыкального образования путем обоснования ее социально-культурных доминант. На основе рассмотрения действующих программ «Музыка» в Чувашской Республике в контексте их социально-культурной ориентированности дается описание факультативного курса «Музыкальное путешествие по родному краю» для начальных классов общеобразовательных школ Чувашии, который базируется на национальном музыкально-художественном материале. Данный факультативный курс опирается на результаты факторного анализа, обосновывающего те социально-культурные доминанты содержания курса, которые направлены на формирование у детей комплекса как музыкальных, так и этнокультурных знаний в целом, умений и представлений в области национальной культуры. Согласно Л. Г. Арчажниковой, «профессия учителя музыки требует от избравшего ее постоянного совершенствования своей личности, развития музыкальных интересов, творческих способностей. Идеалы профессии меняются с развитием общества, зависят от его идеалогии и культуры, и вместе с тем основой профессии учителя музыки всегда является гуманистическая устремленность и неразрывная связь с музыкальным искусством» [3]. Цель исследования заключается в научном обосновании и разработке методической системы формирования у детей младшего школьного возраста компетенций в области национальной культуры на основе раскрытия творческого потенциала каждого учащегося в процессе музыкально-творческой деятельности на уроках музыки по разработанной автором данной статьи программе факультативного курса «Музыкальное путешествие по родному краю».

Актуальность исследуемой проблемы обусловлена высоким интересом к национальной культуре как к значимому для воспитания явлению. Это объясняется тем, что именно культура является содержанием воспитания, материалом, на котором оно строится [4]. Знание культуры родного края, понимание и освоение ее ценностных основ - 
важнейшие задачи образования, и в то же время значимое средство воспитания гражданина своего Отечества. По мнению Л. В. Кузнецовой, С. Г. Григорьевой, «Национальнокультурная среда является системным образованием в образовательном пространстве современной школы. В ней сконцентрированы регионально-культурные художественные ценности, составляющие учебный и предметный компоненты, отраженные в культурноисторических традициях» [7]. При всех изменениях, происходящих в политике и социальной сфере, восприятие детьми национальных традиций народов, населяющих Россию, как важнейшей гуманитарной ценности позволяет им ощутить себя частью великой России, ее славной истории и большого будущего. Пониманию всего этого способствует развитая эмоциональная сфера личности ребенка, в формировании которой непреходящее значение имеют музыка, музыкальное образование. Известно, что культурное богатство России составляет ее многонациональность, поэтому региональные программы общего музыкального образования необходимо рассматривать с учетом сложившихся музыкальных традиций, а также в контексте современной социокультурной ситуации, затрагивающей музыкальное образование как важнейшую гуманитарную сферу общества и государства. Из анализа следует, что «с учетом местных условий в Чувашии разработаны учебные пособия и региональные программы по музыке. Это учебное пособие Л. В. Кузнецовой "Художественная культура родного края" (1996 г.), факультативный курс Е. В. Бакшаевой "Музыкальное путешествие по родному краю" для I-III классов (2004 г.), программа по чувашской музыке для 1-8 классов под редакцией Л. В. Кузнецовой (2008 г.)» [9], [10]. Благодаря данным программам и хрестоматиям учителя музыки имеют возможность разнообразить и пополнять репертуар урока музыки в общеобразовательной школе.

Материал и методы исследования. Известный педагог О. А. Апраксина говорила о том, что «главной задачей массового музыкального воспитания в общеобразовательной школе является не столько обучение музыке само по себе, сколько воздействие через музыку на весь духовный мир учащихся, прежде всего на их нравственность» [2]. Целью программы данного курса является «формирование национальной культуры школьника с опорой на межпредметные связи в сфере национальной культуры (изобразительное и декоративно-прикладное искусство, устный и музыкальный фольклор), где главным средством обучения является музыка, способная глубоко затронуть душу ребенка, активизировать мышление, восприимчивость, творческий потенциал, прививая ему хороший музыкальный вкус» [5].

Для реализации данной цели в исследовании были использованы как теоретические (изучение и анализ литературы по проблеме исследования), так и эмпирические методы (наблюдение, опрос, анкетирование; обобщение собственного педагогического опыта; опытно-экспериментальная работа с учащимися, включающая констатирующий и обучающий этапы, срезы, обследования; анализ опытно-экспериментальных данных).

Результаты исследования и их обсуждение. Программа данного курса представлена таким образом, что в учебной четверти реализуются две темы, представленные в преемственности. К примеру, если первая тема посвящена знакомству детей с традиционными народными музыкальными инструментами, с особенностями праздничной одежды чувашей - чувашского национального костюма, музыкальному оформлению народных праздников и др., то вторая тема имеет деятельностно-творческий характер. Здесь учащихся уже сами должны участвовать в исполнении произведений музыкального фольклора и традиционных праздников чувашского народа через разыгрывание (инсценирование) праздников, используя элементы народных танцев, подыгрывая на народных инструментах, включая ритмические импровизации. Таким образом, тематическое построение программы каждой учебной четверти в полной мере отражает логику освоения образцов традиционной чувашской музыкальной культуры: от знания о ней - к практическому воплощению знаний на творческой практике. 
Как подчеркивает Л. В. Кузнецова, «в качестве фундаментальных основ гуманитарного образования, в частности музыкального, необходимо рассматривать демократичность, гуманизм, учет исторических и культурных ценностей, этнокультурных особенностей народов, что отражает его региональный аспект» [8]. Содержание курса знакомит школьников с чувашскими народными песнями, произведениями композиторов старшего поколения, такими как Г. Лискова, Ф. Павлова, Ф. Лукина, Г. Хирбю, Г. Воробъева, В. Ходяшева и др., с музыкой современных чувашских композиторов: А. Галкина, Л. Быренковой, В. Салиховой, с чувашскими народными сказками о музыке и музыкальных инструментах: «Песня», «Лиса-плясунья», «Волынка с сорока рожками» и т. д. Школьники узнают историю создания первой чувашской оперы и первого чувашского балета. Кроме этого, предлагается знакомство с детскими спектаклями современных чувашских композиторов: Н. Наумова «Старикова дочь», В. Салиховой на текст Р. Сарби «Бабушкина сказка» и т. д. Также в программе предусмотрено знакомство с репродукциями картин чувашских художников: А. Миттова, М. Спиридонова, Р. Зайцева и других.

Основываясь на утверждении К. А. Кашаевой, Л. В. Кузнецовой о важности «помнить, что конечной целью музыкального образования и воспитания является научить ребенка слышать, любить и понимать музыку, чувствовать ее красоту. При этом необходимо помнить, что лучший способ развития ребенка находится именно в деятельности, когда ребенок сам поет, сам рисует, лепит, танцует, играет» [6]. В основе тематического содержания курса ясно прослеживается принцип связи народного искусства с жизнью, поэтому освоение детьми учебных тем происходит органично, естественным образом на основе дополнения и взаимного обогащения. Отметим, что использование в работе проблемнопоискового метода позволяет рассматривать познание и освоение нового как процессов местной деятельности педагога и детей на основе живого интереса. Дело в том, что направленность программы факультативного курса «Музыкальное путешествие по родному краю» отражает особенности детей младшего школьного возраста, психологию восприятия ими произведений искусства: это синкретизм восприятия, особая эмоциональность, яркая способность к сопереживанию, наконец, отождествление себя с героями сказок.

Познавательная и эвристическая деятельности органически сочетаются на музыкальных занятиях данного курса, в котором методической основой занятий становятся такие формы и методы работы, как диалог-беседа, размышления вслух и т. д. Каждое занятие пронизано атмосферой творчества, так как игровая и импровизационная деятельности являются самыми доступными формами осмысления и отражения действительности в младшем школьном возрасте. Творческие задания программы факультативного курса способствуют формированию и развитию активного восприятия, воображения и на этой основе развитию ассоциативного мышления.

Одним из активных приемов включения детей в творческую деятельность, достаточно эффективным, является движение под музыку, вернее, исполнение музыки в движении. Здесь детям необходимо «войти в образ» путем пластического интонирования, т. е. передачи музыкальной интонации и ее развития в свободном движении руками, всем корпусом, выполнить задание означает «почувствовать музыку всем телом». Здесь важно настроиться на музыку, передать ее настроение через простые, но выразительные движения, в нашем примере - основные элементы чувашских танцев.

С большим интересом дети исполняют чувашские плясовые и наигрыши на детских музыкальных инструментах, и это тоже направлено на активизацию у них музыкального восприятия. Этот вид творческой деятельности ценен и тем, что создает у школьников впечатление непосредственного участия в инструментальном сопровождении какоголибо народного праздника. 
Э. Б. Абдуллин утверждал: «Потребность в деятельности выражается в живом увлечении самим его процессом, в желании двигаться, оперировать словами, звуками, красками. Коммуникативная потребность выступает как стремление к эмоциональному общению, как желание испытать, пережить разнообразную гамму эмоциональных состояний, заслужить одобрение взрослого, испытать новые яркие чувства» [1]. Эффективному раскрытию творческого потенциала каждого школьника способствует вовлечение в процесс коллективного творчества: сочинение различных мелодий на предложенный текст, диалогов в инсценировках чувашских народных сказок, выполнение иллюстраций к народным сказкам, музыкальным произведениям, участие в разработке эскизов костюмов, декораций музыкальных сказок и спектаклей. Кульминацией каждого года обучения становится постановка жанрового спектакля: театрализация народной сказки, инсценировки народной сказки, народного праздника, фрагмента детской оперы, музыкальной сказки.

Рассмотрим тематическое содержание программы «Музыкальное путешествие по родному краю». Первый класс объединяет тема «Музыка в жизни чувашей». Учащимся для знакомства предлагаются чувашские народные песни и танцы, а также народные сказки и репродукции картин чувашских художников, в которых рассказывается о природе родного края, национальных музыкальных инструментах, о школе, детских играх и т. д. Таким образом, школьники знакомятся с произведениями разных видов национального искусства на близкие и понятные им темы, гордятся культурой своего народа. Программа второго класса подчинена теме «Народный календарь». Постигая необъятный мир народных праздников, обрядов, традиций, школьники начинают осознавать, что именно им в дальнейшем предстоит быть основными хранителями родной культуры, носителями народной мудрости древних песен и легенд. Обогащается запас полученных в первом классе музыкальных и литературно-художественных впечатлений, закрепляются и развиваются приобретенные умения и навыки.

Программу третьего года обучения объединяет тема «Музыкальные полотна». Школьники получают представление о чувашском музыкальном театре, произведениях чувашских композиторов для детей. Они осознают, что фольклор служит основой для возникновения и развития профессионального музыкального искусства Чувашии» [5].

Таким образом, тематический план программы факультативного курса «Музыкальное путешествие по родному краю» (см. таблицу 1) позволяет проследить логику постижения школьниками народной музыкальной культуры на примере музыкального искусства чувашского народа, ее направленность на освоение традиционных общественных ценностей как неотъемлемой части всей жизни народа.

Тематический план программы факультативного курса «Музыкальное путешествие по родному краю»

\begin{tabular}{|c|l|l|}
\hline $\begin{array}{l}\text { №№ } \\
\text { п/п }\end{array}$ & \multicolumn{1}{|c|}{ Класс, название темы } & \multicolumn{1}{|c|}{ Количество часов } \\
\hline 1. & Первый класс: «Музыка в жизни чувашей» & $\mathbf{3 6}$ ч. \\
& І четверть. & $\mathbf{9}$. \\
& Тема 1: «Чувашия - край ста тысяч песен!» & 5 ч. \\
& Тема 2: «Осенний хоровод» & 4 ч. \\
& II четверть. & $\mathbf{8}$. \\
& Тема 3: «Музыкальные инструменты моего народа» & 4 ч. \\
& Тема 4: «Здравствуй, зимушка-зима!» & 4 ч. \\
& IІІ четверть. & $\mathbf{1 0}$ ч. \\
& Тема 5: «Танец в жизни моего народа» & 5 ч. \\
& Тема 6: «Весенняя капель» & 5 ч. \\
\hline
\end{tabular}




\begin{tabular}{|c|c|c|}
\hline & $\begin{array}{l}\text { IV четверть. } \\
\text { Тема 7: «Музыкальные картинки о нас» } \\
\text { Тема 8: «Музыкальные краски лета» }\end{array}$ & $\begin{array}{l}9 \text { ч. } \\
4 \text { ч. } \\
5 \text { ч. }\end{array}$ \\
\hline 2. & $\begin{array}{l}\text { Второй класс: «Народный календарь» } \\
\text { I четверть. } \\
\text { Тема 1: «Музыкальные краски школы» } \\
\text { Тема 2: «Музыкальный карнавал животных» } \\
\text { II четверть. } \\
\text { Тема 3: «Народный календарь (зима)» } \\
\text { III четверть. } \\
\text { Тема 4: «Юмор и шутка в музыке» } \\
\text { Тема 5: «Народный календарь (весна)» } \\
\text { IV четверть. } \\
\text { Тема 6: «Народный календарь (лето)» } \\
\text { Тема 7: «Музыкальное путешествие в деревню» }\end{array}$ & $\begin{array}{l}36 \text { ч. } \\
9 \text { ч. } \\
4 \text { ч. } \\
5 \text { ч. } \\
9 \text { ч. } \\
9 \text { ч. } \\
10 \text { ч. } \\
4 \text { ч. } \\
6 \text { ч. } \\
8 \text { ч. } \\
4 \text { ч. } \\
4 \text { ч. } \\
\end{array}$ \\
\hline 3. & $\begin{array}{l}\text { Третий класс: «Музыкальные полотна» } \\
\text { І четверть. } \\
\text { Тема 1: «Инструментальная и вокальная музыка» } \\
\text { Тема 2: «Что такое мюзикл?» } \\
\text { II четверть. } \\
\text { Тема 3: «Чувашские музыкальные сказки». } \\
\text { Ш четверть. } \\
\text { Тема 4: «Чувашская опера» } \\
\text { Тема 5: «Чувашский балет» } \\
\text { IV четверть. } \\
\text { Тема 6: «Композиторы Чувашии - детям!» } \\
\text { Тема 7: «Что выражает и изображает музыка?» }\end{array}$ & $\begin{array}{l}36 \text { ч. } \\
9 \text { ч. } \\
5 \text { ч. } \\
4 \text { ч. } \\
8 \text { ч. } \\
8 \text { ч. } \\
10 \text { ч. } \\
5 \text { ч. } \\
5 \text { ч. } \\
9 \text { ч. } \\
5 \text { ч. } \\
4 \text { ч. } \\
\end{array}$ \\
\hline & & 108 ч. \\
\hline
\end{tabular}

Проведенный анализ данных программ показывает следующее: 1) глобализация образования, затрагивающая школьные предметы гуманитарного и художественноэстетического циклов, не должна нивелировать этническое своеобразие народных культур, которое ярко представлено их музыкальными традициями, направленными на воспитание в ребенке любви к родному краю, к Отечеству; 2) в некоторых из анализируемых программ в недостаточной степени применяется принцип художественной интеграции на уроках музыки, а также метод художественного контекста. Тем самым не уделяется должного внимания культуроемкости региональных программ школьного музыкального образования. Следовательно, актуальными социокультуроемкими основами, т. е. доминантами содержания региональной программы общего музыкального образования, определены следующие: 1) воспитание патриотов своей малой родины и России; 2) гуманистическая, культуротворческая направленность профессиональной деятельности педагога-музыканта; 3) этнокультурная толерантность как механизм формирования гражданского самосознания обучающихся. Необходимо отметить, что данный курс содержит материалы из области чувашской художественной культуры, музыкального искусства, тем самым предоставляет школьникам большие возможности для реализации творческих способностей. В унисон этому положению звучат слова Б. В. Асафьева: «Каждый, кто хоть немного ощутил в какой-либо сфере искусства радость творчества, будет в состоянии воспринимать и ценить все хорошее, что делается в этой сфере» [3].

Выводы. Проанализировав региональные программы по музыке, отметим, что разработанная нами методика может быть использована в содержании курсов методики музыкального обучения и воспитания в различных образовательных системах республики, в общеобразовательных школах, детских школах искусств, музыкально-педагогических колледжах, на музыкально-педагогических факультетах и факультетах начальных классов педагогических вузов; может входить в содержание курсов по специализации и повышению квалификации учителей музыки. 


\section{ЛИТЕРАТУРА}

1. Абдуллин Э. Б. Теория и практика музыкального обучения в общеобразовательной школе. - М. : Просвещение, 1983. - 112 с.

2. Апраксина О. А. Из истории музыкального воспитания. - М. : Просвещение, 1990. -207 с.

3. Арчажникова Л. Г. Профессия - учитель музыки. - М. : Просвещение, 1984. - 110 с.

4. Асафьев Б. В. Избранные статьи о музыкальном просвещении и образовании. - Л. : Музыка, 1973. - 144 с.

5. Бакшаева $E$. B. Методика создания альтернативных программ по предмету «Музыка» с учетом национально-региональных особенностей : дис. ... канд. пед. наук : 13.00.02. - М., 2003. - 286 с.

6. Камаева К. А., Кузнецова Л. В. Деятельностный подход в музыкальном воспитании школьников // Научное сообщество студентов: проблемы художественного и музыкального образования. - Чебоксары : Чуваш. гос. пед. ун-т, 2019. - С. 169-174.

7. Кузнещова Л. В., Григорьева С. Г. Дидактический анализ национально-культурной среды школьника // Гуманитарные науки и образование. - 2018. - Т. 9, № 2(34). - С. 52-57.

8. Кузнецова Л. В. Музыкальное образование как отражение этнического в поликультурной общности Россиян // Музыкальное и художественное образование: опыт, традиции, инновации. - Чебоксары : Чуваш. гос. пед. ун-т, 2016. - С. 5-8.

9. Кузнецова Л. В. Художественная культура родного края (1-3 классы) : учебное пособие. - Чебоксары : Клио, 1996. - 40 с.

10. Программа по чувашской музыке для 1-8 классов / под ред. Л. В. Кузнецовой. - Чебоксары : Изд-во ЧРИО, 2008. - 103 с.

Статья поступила в редакцию 17.07.2020

\section{REFERENCES}

1. Abdullin E. B. Teoriya i praktika muzykal'nogo obucheniya v obshcheobrazovatel'noj shkole. - M. : Prosveshchenie, 1983. $-112 \mathrm{~s}$.

2. Apraksina O. A. Iz istorii muzykal'nogo vospitaniya. - M. : Prosveshchenie, 1990. $-207 \mathrm{~s}$.

3. Archazhnikova L. G. Professiya - uchitel' muzyki. - M. : Prosveshchenie, 1984. - $110 \mathrm{~s}$.

4. Asaf'ev B. V. Izbrannye stat'i o muzykal'nom prosveshchenii i obrazovanii. - L. : Muzyka, 1973. - $144 \mathrm{~s}$.

5. Bakshaeva E. V. Metodika sozdaniya al'ternativnyh programm po predmetu «Muzyka»s uchetom nacional'no-regional'nyh osobennostej : dis. ... kand. ped. nauk : 13.00.02. - M., 2003. $-286 \mathrm{~s}$.

6. Kashaeva K. A., Kuznecova L. V. Deyatel'nostnyj podhod v muzykal'nom vospitanii shkol'nikov // Nauchnoe soobshchestvo studentov: problemy hudozhestvennogo i muzykal'nogo obrazovaniya. - Cheboksary : Chuvash. gos. ped. un-t, 2019. - S. 169-174.

7. Kuznecova L. V., Grigor'eva S. G. Didakticheskij analiz nacional'no-kul'turnoj sredy shkol'nika // Gumanitarnye nauki i obrazovanie. - 2018. - T. 9, № 2(34). - S. 52-57.

8. Kuznecova L. V. Muzykal'noe obrazovanie kak otrazhenie etnicheskogo v polikul'turnoj obshchnosti Rossiyan // Muzykal'noe i hudozhestvennoe obrazovanie: opyt, tradicii, innovacii. - Cheboksary : Chuvash. gos. ped. un-t, 2016. - S. 5-8.

9. Kuznecova L. V. Hudozhestvennaya kul'tura rodnogo kraya (1-3 klassy) : uchebnoe posobie. - Cheboksary : Klio, 1996. $-40 \mathrm{~s}$.

10. Programma po chuvashskoj muzyke dlya 1-8 klassov / pod red. L. V. Kuznecovoj. - Cheboksary : Izd-vo ChRIO, 2008. - $103 \mathrm{~s}$.

The article was contributed on July 17, 2020

\section{Сведения об авторе}

Бакшаева Елена Владимировна - кандидат педагогических наук, доцент кафедры теории, истории, методики музыки и хорового дирижирования Чувашского государственного педагогического университета им. И.Я. Яковлева, г. Чебоксары, Россия; е-mail: lenabakshaeva14@gmail.com

\section{Author information}

Bakshaeva, Elena Vladimirovna - Candidate of Pedagogics, Associate Professor of the Department of Theory, History, Methods of Music and Choral Conducting, I. Yakovlev CHSPU, Cheboksary, Russia, Cheboksary, Russia; e-mail: lenabakshaeva14@gmail.com 